\title{
REVISIÓN BIBLIOGRÁFICA
}

\section{EFECTO DE LA SUPLEMENTACIÓN LIPÍDICA SOBRE ÁCIDOS GRASOS EN LECHE DE VACA, ÉNFASIS EN ÁCIDO RUMÉNICO ${ }^{1}$}

\author{
Esperanza Prieto-Manrique ${ }^{2}$,Liliana Mahecha-Ledesma ${ }^{3}$,Joaquín Angulo-Arizala ${ }^{3}$, \\ Julio Ernesto Vargas-Sánchez ${ }^{4}$
}

\section{RESUMEN}

Efecto de la suplementación lipídica sobre ácidos grasos en leche de vaca, énfasis en ácido ruménico. El objetivo del presente trabajo fue realizar una revisión sobre el efecto de la suplementación con lípidos sobre la concentración de ácido linoleico conjugado (ALC-c9t11) o ruménico y otros ácidos grasos insaturados en la leche bovina. Se abordó el concepto y origen del ALC-c9t11 en rumiantes. Existe una tendencia internacional en mejorar la calidad de la alimentación, lo que implica el incremento de consumo de proteína animal, dentro de lo cual están los productos lácteos saludables y ricos en ALC-c9t11, que ha mostrado efectos anticancerígenos en modelos animales. En la leche bovina ALC-c9t11, resulta del consumo de ácidos grasos insaturados y de la extensión de la biohidrogenación ruminal. La suplementación con ácidos grasos insaturados de origen vegetal permite aumentar la concentración de ALC-c9t11 y disminuir la proporción de ácidos grasos saturados en la leche, pero la respuesta varía de acuerdo con la fuente de grasa empleada, su nivel y la interacción con la dieta basal.

Palabras clave: ácidos grasos insaturados, biohidrogenación ruminal, glándula mamaria.

\begin{abstract}
Effect of lipid supplementation on milk fatty acid focus on rumenic acid. The aim of this study was to review the effect of the lipid supplementation on the concentration of conjugated linoleic acid (CLA-c9t11) or rumenic acid and other unsaturated fatty acids in bovine milk. The study addressed the concept and origin of the CLA-c9t11 in ruminants. There is an international trend to improve nutrition quality, which implies an increase in consumption of animal protein, including the healthy and rich in CLA-c9t11 dairy products. CLA-c9t11 has proved to have anticancer effects in animal models. CLA-c9t11 in the bovine milk results from the consumption of unsaturated fatty acids and from the extent of rumen biohydrogenation. Supplementation with unsaturated fatty acids of vegetable origin allows to increase the concentration of CLA-c9t11 and to decrease the proportion of saturated fatty acids in milk, but the response varies depending on the source of fat used, its level, and its interaction with basal diet.
\end{abstract}

Keywords: unsatured fatty acids, rumen biohydrogenation, mammary gland.

\footnotetext{
Recibido: 25 de noviembre, 2015. Aceptado: 2 de febrero, 2016. Este trabajo forma parte de un proyecto de investigación financiado por COLCIENCIAS - Colombia y es parte de la tesis doctoral del primer autor.

2 Universidad de Sucre. Facultad de Ciencias Agropecuarias. Carrera 28 N 5-267, Barrio Puerta Roja, Sincelejo -Sucre, Colombia. esperanza. prieto@unisucre.edu.co

3 Universidad de Antioquia. Facultad de Ciencias Agrarias, Grupo de Investigación en Ciencias Animales -GRICA. Sede Robledo, Carrera 75 N ${ }^{\circ}$ 65-87 bloque 46, Medellín - Antioquia, Colombia. joaquin.angulo@udea.edu.co, liliana.mahecha@udea.edu.co (autor para correspondencia).

4 Universidad de Caldas. Facultad de Ciencias Agropecuarias. Departamento de Producción Agropecuaria. Calle 65 N²6-10, Manizales Caldas, Colombia. jvargas@ucaldas.edu.co
}

(C) 2016 Agronomía Mesoamericana es desarrollada en la Universidad de Costa Rica y se encuentra licenciada con Creative Commons Reconocimiento-NoComercial-SinObraDerivada 3.0 Costa Rica. Para más información escríbanos a pccmca@ucr.ac.cr 


\section{INTRODUCCIÓN}

En los últimos años, existe una tendencia internacional de los consumidores orientada a la mejora en la calidad de la alimentación con el uso de alimentos benéficos para la salud humana, entre los que se incluyen los alimentos funcionales (CNL, 2010). Como alimentos funcionales se consideran aquellos alimentos y/o componentes de este, que poseen propiedades adicionales sobre la salud, que supera el beneficio clásico de un aporte de nutrientes (Milner, 1999).

Estudios con ácido linoleico conjugado (ALC) durante esta última década, han revelado funciones benéficas. El ácido linoleico conjugado $\mathrm{C} 18: 2$ cis 9 , trans 11 (ALC-c9t11), también conocido como ácido ruménico (AR), ha mostrado potenciales beneficios para la salud, observados experimentalmente sobre todo en modelos animales, como agente anti arteriosclerótico, antiinflamatorio, antidiabético y, sobre todo, anticarcinogénico (inhibe la mutagénesis), así como potenciador del sistema inmune (Belury, 2002; Khanal, 2004; Pariza, 2004; Weiss et al., 2004a; Shingfield et al., 2008; Salter, 2013). Además, se ha reportado que el ALC trans10, cis 12 inhibe la síntesis de ácidos grasos, reduciendo la acumulación de grasa corporal en individuos con sobrepeso (Weiss et al., 2004b). Aunque estos efectos no han sido comprobados de forma concluyente en la especie humana.

En términos generales, la concentración total de $\mathrm{ALC}$ en la leche de los rumiantes varían entre un 0,3 y un 2,0\% del total de ácidos grasos de la grasa de leche; entre las distintas especies, la leche de vaca presenta los contenidos más altos de ALC $(0,2$ - 3,7 g ALC/100 $\mathrm{g}$ de grasa), seguida por la de cabra $(0,59-3,24 \mathrm{~g} / 100$ $\mathrm{g}$ de grasa) y la de oveja $(1,17-2,97 \mathrm{~g} / 100 \mathrm{~g}$ de grasa) (Parodi, 2003). En la leche bovina, el ALC resulta del consumo de ácidos grasos (AG) insaturados y de la extensión de la biohidrogenación ruminal (BHR) (Chilliard et al., 2003). La magnitud de las cantidades presentes en la leche está determinada principalmente por factores dietarios (Palmquist et al., 2005). El estudio de los factores que afectan el contenido en ALC de la leche es uno de los temas de investigación más importantes dentro del ámbito de la nutrición de los rumiantes (Chilliard et al., 2003; Chilliard y Ferlay,
2004; Castro et al., 2009; Lee et al., 2009; Prandini et al., 2009; Renna et al., 2010), ya que permite obtener información sobre los mecanismos que aumenten dicho contenido.

En diversos estudios se encontró que la suplementación con lípidos de origen animal (Chouinard et al., 2001; AbuGhazaleh et al., 2003; 2004; Shingfield et al., 2003; 2006) y de origen vegetal (Stanton et al., 2003; Khanal y Olson, 2004), permite aumentar la concentración de ALC-c9t11 en la leche. Este documento presenta una revisión sobre el efecto de la suplementación con lípidos sobre la concentración de ALC-c9t11 y otros AG insaturados en la leche bovina.

\section{ÁCIDO LINOLEICO CONJUGADO (ALC)}

El acrónimo ALC (CLA -“Conjugated linoleic acid" en inglés) es un término que engloba una mezcla compleja de isómeros posicionales y geométricos del ácido linoleico (C18:2 cis9, cis12) con dos dobles enlaces, que se encuentra de forma natural en la grasa de alimentos derivados de rumiantes: carne $\mathrm{y}$, fundamentalmente, productos lácteos. Aunque se han detectado distintos isómeros posicionales (7-9, 8-10, 9-11, 10-12, 11-13, 12-14) y geométricos (cistrans, trans-cis, trans-trans y cis-cis) del ALC en la grasa de la leche, más del $70 \%$ del contenido en ALC corresponde al isómero $\mathrm{C} 18: 2$ cis 9 , trans 11 o ácido ruménico (AR) (Bauman et al., 2003a), al que se atribuyen la mayoría de sus propiedades biológicas (McCrorie et al., 2011). Otro isómero del ALC que está siendo también objeto de investigación por su implicación en la inhibición de la síntesis de grasa en mamíferos, es el C18:2 trans10, cis 12 ; pero su contenido en la grasa láctea es muy bajo (menos del $0.1 \%$ sobre el total de ácidos grasos y menos del $1 \%$ sobre el total de ALC), aunque se han encontrado valores de 2,9\% del total de ALC, suplementando las vacas con aceite de girasol más algas (Angulo et al., 2012a). No obstante, sus efectos sobre la salud humana son cuestionados por la comunidad científica (McCrorie et al., 2011). 


\section{ORIGEN DEL ALC-C9T11 EN RUMIANTES}

\section{Formación de ALC como consecuencia de la biohidrogenación ruminal (BHR) de ácidos grasos}

Los lípidos consumidos por los animales están formados por triglicéridos, en el caso de las semillas oleaginosas, y por fosfolípidos y galactolípidos, en el caso de los forrajes y otros alimentos de origen vegetal.

En el rumen estos lípidos sufren dos procesos metabólicos: lipólisis y bio-hidrogenación. Durante la lipólisis, los enlaces éster entre los ácidos grasos y el glicerol o la galactosa se rompen por medio de diversas enzimas microbianas (por ejemplo, lipasas, galactosidasas, fosfolipasas). El glicerol y la galactosa son fermentados formándose ácidos grasos volátiles propiónico y acético, respectivamente. La lipólisis ruminal de los tri y di-glicéridos, corre a cargo de la bacteria Anaerovibrio lipolytica, la cual es muy sensible al $\mathrm{pH}$ del rumen, por lo que en condiciones de acidosis, la lipólisis se ve reducida significativamente. Asimismo, Butyrivibrio fibrisolvens hidroliza fosfolípidos (Dehority, 2003) y diferentes galactosidasas y fosfolipasas (e.g., fosfolipasa A y fosfolipasa C), producidas por microbios del rumen, catalizan la hidrólisis de fosfolípidos y galactolípidos de las plantas (Jenkins, 1993). Los protozoos ciliados poseen actividad lipasa, pero no los hongos (Dehority, 2003), aunque su contribución es más baja que la de las bacterias.

Después de la lipólisis los ácidos grasos insaturados son biohidrogenados por los microorganismos del rumen (isomerasas y reductasas). Este proceso (Figura 1) convierte los ácidos grasos insaturados en ácidos grasos saturados, vía isomerización a ácidos grasos intermediarios trans, seguido por hidrogenación de los dobles enlaces (Harfoot y Hazlewood, 1997).

Así, la biohidrogenación consiste en una primera isomerización: la forma geométrica cis de los dobles enlaces pasa a la forma trans (más estable en el rumen). De esta forma, el doble enlace en posición 12 del ácido linoleico, es transferido con configuración trans al carbono 11, para dar lugar a ALC cis9, trans 11 , en $30 \%$ en vacas (Piperova et al., 2002) y a proporciones variables de diferentes isómeros conjugados y no conjugados (trans9, cis11; trans 10 , cis 12 ; etc) (Jenkins et al., 2008). Posteriormente, tiene lugar una hidrogenación progresiva de los dobles enlaces y se produce una rápida hidrogenación del enlace $c i s 9$, para
(A)

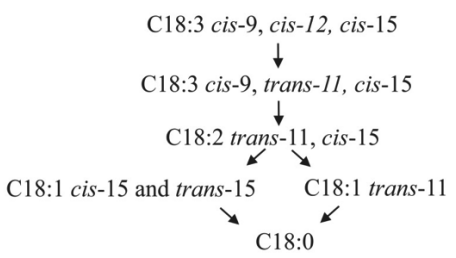

(B)

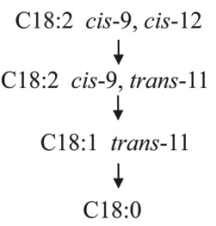

(C)

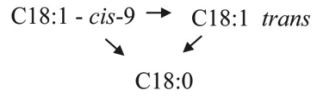

C18:0

Figura 1. Vías de biohidrogenación de los ácidos (A) $\alpha$-linolénico, (B) linoleico y (C) oleico. Adaptado de Harfoot y Hazlewood (1988).

Figure 1. Biohydrogenation pathways of (A) $\alpha$-linolenic, (B) linoleic, and (C) oleic acids. Adapted from Harfoot and Hazlewood (1988).

formar ácido transvaccénico (C18:1 trans11) (ATV), y una segunda sobre el enlace trans11, para dar lugar finalmente a ácido esteárico (C18:0). Sin embargo, en función de diversos factores, la hidrogenación ruminal podría quedar incompleta, dando lugar a un flujo al duodeno de ácidos grasos insaturados y determinados metabolitos intermedios (Stanton et al., 2003), que pueden llegar a absorberse en el intestino y aparecer en los productos finales (leche y carne).

La biohidrogenación del ácido linolénico (C18:3 cis 9 , cis12, cis15) comienza igualmente con la isomerización del enlace cis 12 a trans 11 , posteriormente se produce ATV pero a partir de C18:2 trans 11 , cis 15 (Loor et al., 2004). Existe discrepancia si durante este proceso se forma ALC-c9t11. Lee y Jenkins (2011) demostraron en cultivos continuos de fermentación, que los microorganismos ruminales en mezcla, obtenidos del rumen de ganado, son capaces de formar isómeros C18:3 y diferentes ALC, incluido el ALC-c9t11; aunque en proporción menor al 15\%, indicando que las vías de biohidrogenación del ácido linolénico son más complejas que las reportadas previamente.

En el caso del ácido oleico, no ocurre solamente la biohidrogenación a ácido esteárico sino que, además, se forman numerosos isómeros trans (Mosley et al., 2002) y parte del ácido oleico es transformado en los ácidos 10-hidroxiesteárico y 10-cetoesteárico, como demostraron Jenkins et al. (2006). Cuando se 
suplementan las dietas de ganado vacuno con grasas ricas en ácido oleico (AG mono-insaturado), también se han observado incrementos en los niveles de ALCc9t11 (Secchiari et al. 2003; Collomb et al., 2004a), aunque estos aumentos son menos importantes que cuando se utilizan aceites vegetales ricos en ácidos grasos poli-insaturados.

La velocidad a la que el ATV es reducido a ácido esteárico es más lenta que los pasos previos; en consecuencia, la acumulación de ATV facilita que una parte del mismo escape del rumen y sea disponible para la absorción intestinal (Bauman et al., 1999). El ALC-c9t11 junto a diferentes ácidos grasos trans mono-insaturados, fundamentalmente el ATV, serían los intermediarios más destacados de este proceso de hidrogenación.

La biohidrogenación se realiza por acción de diversas enzimas (isomerasas y reductasas) microbianas. Entre las bacterias ruminales responsables de la biohidrogenación de los ácidos grasos, Butyrivibrio fibrisolvens (Kepler y Tove, 1967; Fukuda et al., 2006; Wallace et al., 2007) en los pasos iniciales y Butyrivibrio proteoclasticus (Moon et al., 2008) en el paso final (reducción a ácido esteárico), jugarían el papel más relevante (Figura 2), aunque se sabe que otras bacterias como Ruminococcus, Eubacterium, Fusocillus (Palmquist et al., 2005; Wallace et al., 2007) y Propionibacterium acnes (McKain et al., 2010), pueden estar también implicadas.

Los hongos del rumen, pueden biohidrogenar ácido linoleico obteniendo como producto final ATV, pero su biohidrogenación es más baja que la realizada por las bacterias del rumen, siendo Orpinomyces el hongo más activo (Nam y Garnswotrhy, 2007). Con respecto a los protozoos existe contradicción, Jenkins et al. (2008), en su revisión concluyeron que los protozoos no producen por sí mismos ALC-c9t11, ni ATV; sin embargo, mediante ellos se pueden obtener estos ácidos, disponibles para el animal. No obstante, otros autores, plantean que los protozoos influyen en el contenido de intermediarios de la BHR por las isomerasas, y que la mezcla de bacterias y protozoos tiene una mayor capacidad para biohidrogenar ácido linoleico, que las bacterias solas (Or-Rashid et al., 2011; Buccioni et al., 2012) (Figura 3).

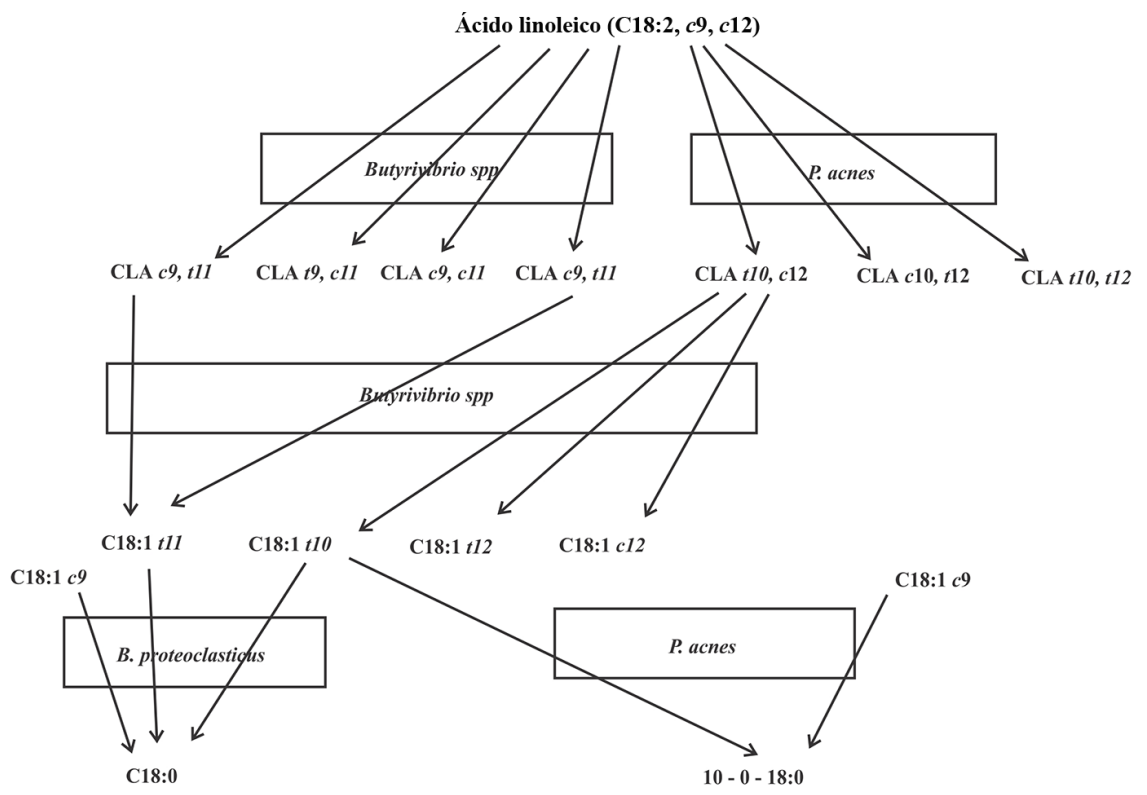

Figura 2. Papel de Butyrivibrio spp., Propionibacterium acnes y Butyrivibrio proteoclasticum sobre el metabolismo de los ácidos grasos insaturados linoleico y oleico. Tomado de McKain et al. (2010) y Wallace et al. (2006).

Figure 2. Role of Butyrivibrio spp., Propionibacterium acnes and Butyrivibrio proteoclasticum on the metabolism of the unsaturated linoleic and oleic fatty acids. From McKain et al. (2010) and Wallace et al. (2006). 


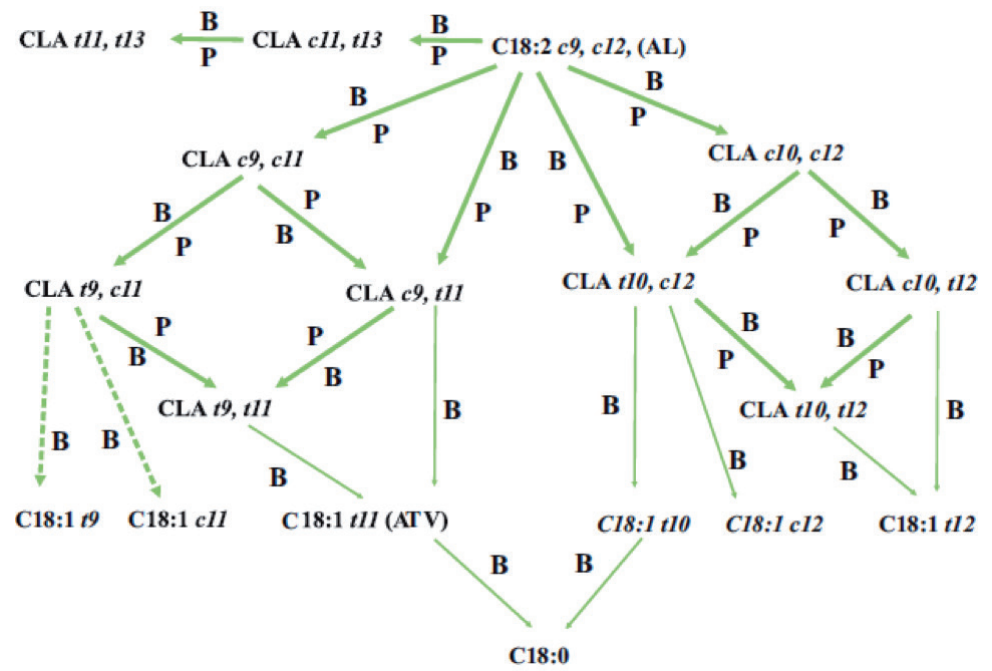

Figura 3. Vías metabólicas para la biosíntesis de ALC y compuestos relacionados de ácido linoleico por bacterias del rumen (B) y protozoos (P). Flechas sólidas más gruesas son actividades bacterianas y protozoarias que conducen a la formación de isómeros de ALC y C18: 1, incluyendo C18:0, las flechas punteadas son la actividad bacteriana que conduce a la formación de los compuestos posibles y las flechas continuas delgadas representan las actividades bacterianas. Tomado de Or-Rashid et al. (2011).

Figure 3. Metabolic pathways for biosynthesis of CLA and related compounds from linoleic acid by rumen bacteria $(\mathrm{B})$ and protozoa $(\mathrm{P})$. Thicker solid arrows show bacterial and protozoa activities leading to the formation of isomers of CLA and C18:1, including C18:0, the dotted arrows show the bacterial activity leading to the formation of the possible compounds, and the thin solid arrows show bacterial activities. From Or-Rashid et al. (2011).

Las tasas de lipólisis y biohidrogenación, dependen del tipo y la cantidad de grasa que ingresa al rumen (Beam et al., 2000) y del pH ruminal (Van Nevel y Demeyer, 1996). El proceso de biohidrogenación no deja de ser un mecanismo de defensa de los microorganismos ruminales para reducir la toxicidad de los ácidos grasos insaturados. Los ácidos grasos de cadena larga inhiben el metabolismo microbiano, y esta actividad inhibitoria es más elevada cuanto mayor es su grado de insaturación; por lo tanto, la biohidrogenación ruminal (BHR) es modificada a través de toxicidad diferencial sobre las bacterias ruminales de los diferentes ácidos grasos poliinsaturados, incluyendo los ácidos grasos de aceite de pescado, eicosapentaenoico (EPA) y docosahexaenoico (DHA).
Si se puede entender como la toxicidad selectiva de un ácido graso, o incluso otros factores, afectan la fisiología de las bacterias biohidrogenantes del rumen, es posible que se puedan sugerir nuevas modificaciones en la dieta de los animales que finalmente producirían alimentos provenientes de rumiantes más saludables para consumo humano (Maia et al., 2010).

La isomerización previa a la BHR requiere que el grupo carboxilo de la molécula esté libre, lo cual determina que la lipólisis pueda considerarse como la etapa limitante del proceso global y todos los factores que repercuten sobre la lipólisis afecten también a la BHR (Bauman et al., 2003b). La eficacia de la BHR se relaciona negativamente con la proporción de concentrados en la dieta (Sauvant y Bas, 2001). 
De hecho, la BHR es más intensa en dietas con abundantes forrajes (Kucuk et al., 2001; Lee et al., 2006). Cuando disminuye la proporción de forraje, el flujo de isómeros C18:1trans totales hacia el duodeno puede duplicarse (Loor et al., 2004). Ello es debido principalmente a un incremento lineal del flujo del isómero C18:1trans-10, cuya proporción en dichas circunstancias puede pasar del 4 al 25\% del total de isómeros del grupo (Piperova et al., 2002; Loor et al., 2004). En general, todas aquellas características de la dieta, como el tamaño de partícula, proporción de concentrados, exceso de almidón degradable en rumen, ausencia de tampones, que reducen el valor medio diario de $\mathrm{pH}$ ruminal a menos de 6,25 (Sauvant et al., 1999), afectan negativamente a la eficacia de la BHR. Troegeler-Meynadier et al. (2006) comprobaron in vitro que un $\mathrm{pH}<6$ inhibe la isomerización y la segunda reducción, lo cual puede relacionarse con el hecho que las bacterias celulolíticas, principales responsables de la BHR, son muy sensibles a valores de $\mathrm{pH}<6$ (Slyter, 1986; Owens et al., 1998). Otros factores que afectan negativamente a la eficacia de la BHR, son la elevada concentración de los ácidos linoleico (Atkinson et al., 2006; Harvatine y Allen, 2006) y linolénico (Troegeler-Meynadier et al., 2006). También la presencia en el medio ruminal de ácido eicosapentaenoico (EPA) y ácido docosahexaenoico (DHA) inhiben la reducción del ATV (Chow et al., 2004; Lee et al., 2005), la de los ácidos oleico y linoleico (AbuGhazaleh y Jenkins, 2004) y la suya propia (Dohme et al., 2003; Chow et al., 2004).

La BHR está fuertemente influenciada por metabolitos secundarios presentes en las plantas (PSM), que incluye polifenol oxidasa (PPO) y taninos (Lee et al., 2007a; Cabiddu et al., 2009; 2010). La PPO aumentó la protección de los lípidos de la actividad lipolítica y disminuyó la BHR por $11-22 \%$ (Lee et al., 2007b; 2008). Sin embargo, no se pudo concluir definitivamente, a partir de estos resultados, si la protección fue debida a la inhibición de la lipasa o al complejo proteína-fenol y/o lípidos-fenol (Lee et al., 2010). Varios informes sobre la relación entre taninos y metabolismo ruminal mencionan los efectos negativos de la degradación de la proteína y la fibra sobre el desarrollo de la microflora ruminal. Sin embargo, hay poca información disponible sobre los efectos de los compuestos polifenólicos sobre la actividad de la linoleico isomerasa (LA-I) en el rumen
(Cabiddu et al., 2009; 2010). No obstante, Vasta et al. (2009a; b) informaron que los taninos no interfieren con LA-I, pero sí con la proliferación microbiana. Así, los taninos no inhiben la actividad de las enzimas microbianas, pero cambian la composición de la población microbiana ruminal.

En una revisión se sugiere que la lipólisis y BHR están directamente influenciadas por la asociación de PPO, tasa de pasaje, encapsulación de lípidos y otros metabolitos secundarios de las plantas (MSP), $\mathrm{y}$ esto a veces puede conducir a resultados que son aparentemente contradictorios (Buccioni et al., 2012). Por lo tanto, se necesita investigar sobre cómo las interacciones de los factores mencionados influencian la lipólisis, la biohidrogenación y su respectiva jerarquía.

\section{Síntesis endógena en la glándula mamaria}

El ALC-c9t11 contenido en la leche, se origina de la absorción intestinal con posterior transferencia a la glándula mamaria de este ácido graso producido en el rumen, y de su síntesis endógena a partir de ATV por acción de la enzima Delta-9 desaturasa en la glándula mamaria (Bauman y Lock, 2006). Esta última es la principal vía de acumulación de ALC-c9t11 en la leche bovina, se estima que más del 74\% de ALC-c9t11 en la grasa de la leche es sintetizado a través de la actividad de la enzima Delta-9 desaturasa, a partir del ATV que proviene del rumen (Bichi et al., 2012).

Existen pocos estudios detallados sobre el posible origen endógeno de otros isómeros de ALC, quizá porque la mayoría de ellos contribuye con porcentajes muy pequeños a la grasa de leche de vaca, y su significado biológico aún no ha sido clarificado. El trans 7, cis 9 es cuantitativamente el segundo isómero más importante de ALC, constituyendo entre el 3 y el $15 \%$ del total de los isómeros en grasa de origen lácteo. Se sugirió que su síntesis era casi exclusivamente en la glándula mamaria, por medio de la Delta-9 desaturasa a partir del C18:1 trans 7 producido en el rumen por isomerización del ácido oleico (Corl et al., 2002).

Es importante tener en cuenta que la producción de grasa de la leche depende del equilibrio entre el aumento en la transferencia de los AG de la dieta a la glándula mamaria y la disminución de la síntesis de novo. Una disminución en la síntesis de $A G$ dentro de la glándula mamaria, se observa a menudo, cuando 
se añaden fuentes suplementarias de AG a la dieta de vacas lecheras en lactación (Lock y Bauman, 2004).

\section{ESTRATEGIAS PARA AUMENTAR ALC-C9T11 Y ATV EN LECHE}

Se han propuesto estrategias para aumentar el ALC-c9t11 en la grasa de la leche, las cuales se centran en aumentar la cantidad de ATV producido en el rumen e incrementar la actividad de la Delta-9 desaturasa (Figura 4). El aumento de ATV que sale del rumen, se puede conseguir manipulando la dieta y el proceso de biohidrogenación: 1. Aumentando el ingreso de ácidos poliinsaturados linoleico y linolénico (precursores de ATV) al rumen, 2. Manteniendo la vía de formación de trans 11, 3. Inhibiendo el paso de ATV a ácido esteárico. Por lo tanto, el contenido de ALC-c9t11en la grasa de la leche, puede ser notablemente afectado al elegir la combinación de ingredientes de los alimentos, que afectan el suministro dietético de ácidos grasos poliinsaturados y/o afectan el ambiente ruminal, con el fin de alterar la velocidad y la integridad de la biohidrogenación (Bauman y Lock, 2006). Por otra parte, el aumento de la Delta-9 desaturasa se puede conseguir mediante selección genética, dada la alta variabilidad entre vacas para producir leche con alto ALC-c9t11, lo que sugiere avanzar en la obtención de marcadores moleculares indicativos de una alta capacidad individual de generación de ALC y el desarrollo de estudios destinados a cuantificar la expresión del gen responsable de la expresión de la enzima estearil CoA desaturaturasa o Delta-9 desaturasa (Gagliostro, 2004a). Se esperan progresos futuros, mediante el uso de selección asistida por marcadores, para aumentar la frecuencia de genotipos favorables y la formulación de dietas, para aprovechar este potencial genético y mejorar la composición de los ácidos grasos de los alimentos producidos por los rumiantes (Shingfield et al., 2013).

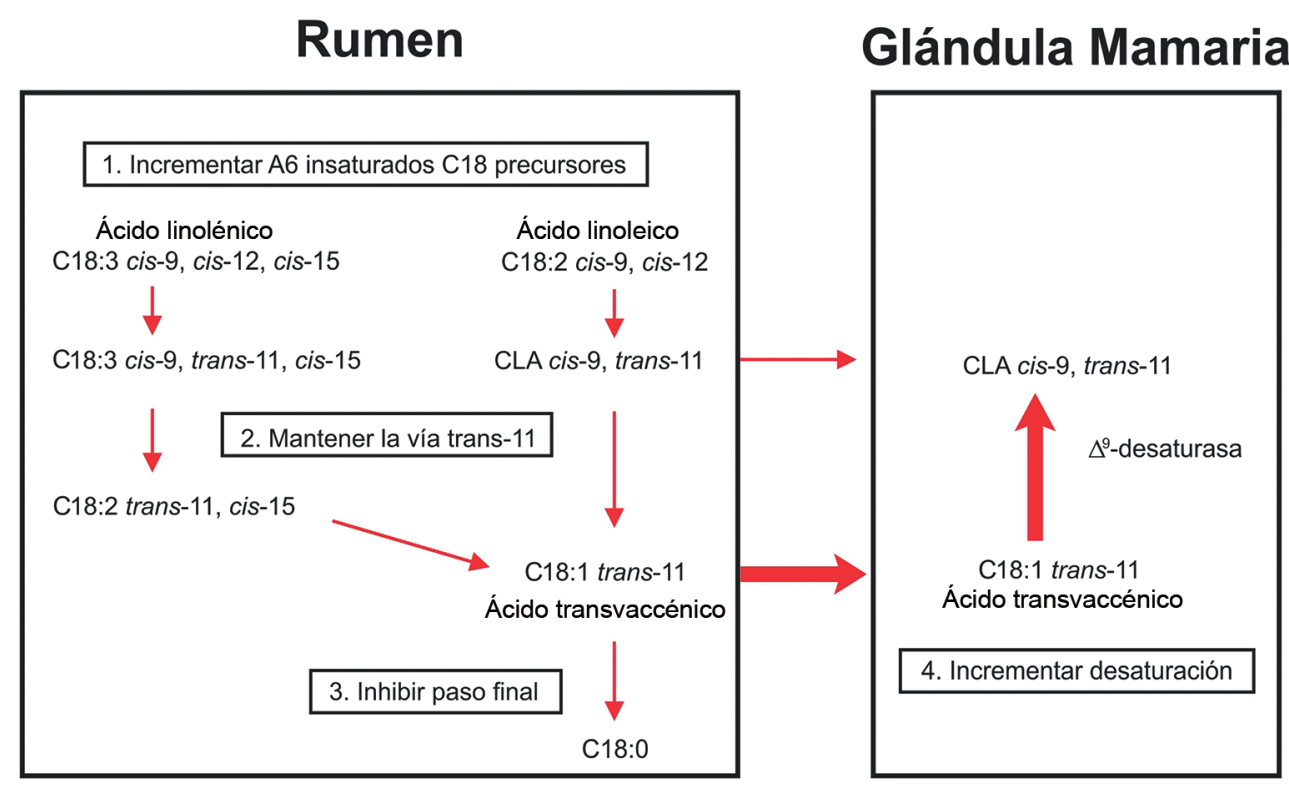

Figura 4. Vías para la síntesis ruminal y endógena de ácido linoleico conjugado (ALC) cis-9, trans-11 en vacas lecheras y estrategias para aumentar el contenido ALC en la grasa de la leche. Adaptado de Bauman y Lock (2006).

Figure 4. Pathways for ruminal and endogenous synthesis of conjugated linoleic acid (CLA) cis-9, trans-11 in dairy cows, and strategies to increase CLA on milk fat content. Adapted from Bauman and Lock (2006). 


\section{EFECTO DE LA ADICIÓN DE LÍPIDOS SOBRE ALC-C9T11 Y ATV}

Una comparación entre diferentes tipos de aceites de origen vegetal sugiere que aquellos con contenidos más altos en los ácidos linoleico y linolénico (como los procedentes de semillas de soja, algodón, girasol, lino, cártamo y colza - Cuadro 1) son los más idóneos para aumentar el ALC-c9t11 en leche (Stanton et al., 2003; Khanal y Olson, 2004). Además, se ha comprobado que aquellos más ricos en ácido linoleico (girasol, soja) son los más efectivos (Kelly et al., 1998; Dhiman et al., 2000; Lock y Garnsworthy, 2002; Collomb et al., 2004b; Hervás et al., 2006; Shingfield et al., 2006). Este efecto es lineal ante la adición de cantidades crecientes de aceite a la ración (hasta 3-4\% de la MS, al menos), con una respuesta de alrededor de $0,4 \%$ de los AG totales por punto de aumento de la concentración de lípidos de la ración para la soja, el girasol o el lino. Este efecto se explica por un fuerte aumento en la producción de ATV en el rumen, el cual es utilizado por la glándula mamaria y desaturado a ALC-c9t11 por la Delta-9 desaturasa. En cambio, un aceite rico en $\mathrm{AG}$ oleico (C18:1 $c 9)$ (oliva, colza) aumenta ligeramente la secreción de ALC-c9t11 (Chilliard et al., 2007b).

La forma de incorporación de estos ácidos grasos insaturados en la dieta del ganado puede jugar un papel importante. La presentación en forma protegida como sales o el empleo de semillas intactas, sin procesar, apenas produce incrementos en los niveles de ALC en leche, ya que hay mínima interacción de estos ácidos grasos a nivel ruminal para la producción del principal precursor de ALC-c9t11. La adición de semillas sometidas a molienda, extrusión, micronización o calentamiento, mejoran los contenidos de ALC-c9t11 en leche (Dhiman et al., 2000; Chouinard et al., 2001; Secchiari et al., 2003). Las formas de suplementación más efectivas para aumentar ALC-c9t11 en la leche, han sido la adición directa de aceite extraído de las semillas o las semillas sometidas a tratamiento térmico previo (Chilliard et al., 2007b). Un rápido y eficaz contacto del aceite con las bacterias ruminales conduce a la acumulación ruminal del precursor ATV (Gagliostro, 2011). Este efecto es particularmente importante cuando las vacas se encuentran en alimentación bajo pastoreo, debido a que la tasa de pasaje resulta más rápida y la población microbiana involucrada en el proceso de biohidrogenación puede verse afectada (Kolver, 1997).

Además de los efectos del tipo de lípidos alimentarios, de su forma de presentación y de la cantidad, existen importantes interacciones con la naturaleza de los forrajes y con la relación forraje:concentrado de la ración (Chilliard et al., 2007b).

El efecto de la suplementación con semillas oleaginosas sobre la proporción de grasa en leche depende de la naturaleza de la semilla (lino, colza), de su forma (extruída, harina en frío, entera sin procesar) y de la interacción con el tipo de dieta basal (ensilaje de hierba, heno o pastura) (Lerch et al., 2012). Asimismo, el efecto de la suplementación con semilla de lino molida sobre la proporción de ácidos grasos de la leche, depende de la relación forraje:concentrado y

Cuadro 1. Porcentaje de ácidos grasos presentes en aceite de diferentes semillas. 2015.

Table 1. Percentage of fatty acids present in different seeds. 2015.

\begin{tabular}{|c|c|c|c|c|c|c|}
\hline \multirow[t]{2}{*}{ Aceite } & Palmítico & Esteárico & Oleico & Linoleico & Linolénico & \multirow[t]{2}{*}{ Autor } \\
\hline & $\mathrm{C} 16: 0$ & C18:0 & $\mathrm{C} 18: 1$ & $\mathrm{C} 18: 2$ & C18:3 & \\
\hline Colza & 4,5 & 1,4 & 61,2 & 23,0 & 9,9 & Rego et al., 2009 \\
\hline Girasol & 5,4 & 2,8 & 26,8 & 64,9 & 0,1 & Rego et al., 2009 \\
\hline Lino & 4,4 & 2,6 & 20,0 & 16,3 & 56,7 & Rego et al., 2009 \\
\hline Girasol & -- & -- & 15,31 & 65,23 & 0,21 & Jacob et al., 2012 \\
\hline Soja & -- & -- & 21,53 & 51,65 & 8,83 & Jacob et al., 2012 \\
\hline Soja & 9,6 & 5,3 & 26,0 & 50,5 & 5,5 & Boerman y Lock, 2014 \\
\hline Soja & -- & -- & 25,0 & 51,0 & -- & Vargas-Bello-Pérez et al., 2015 \\
\hline Semilla de algodón & 19,9 & 2,4 & 17,1 & 58,4 & 0 & Aprianita et al., 2014 \\
\hline
\end{tabular}


del tipo de forraje de la dieta basal, siendo mayores los niveles de C18:1 trans 10, C18:1 trans 15, C18:1 cis $15, \mathrm{C} 18: 2$ trans 11 , cis 15 y C18:3 n-3 en la grasa de la leche, con dietas que contenían 5\% de semilla de lino molida y relación forraje:concentrado de 35:65, comparada con niveles de 1 y $3 \%$ y relación $\mathrm{F}: \mathrm{C}$ de 50:50 o 65:35 (Sterk et al., 2011).

En la mayoría de los estudios realizados se ha observado un aumento del contenido en ALC-c9t11 y ATV al emplear dietas en las que se aportan lípidos ricos en ácidos grasos insaturados. La suplementación con isómeros sintéticos de ALC en forma protegida (Giesy et al., 2002; Perfield et al., 2002; BernalSantos et al., 2003) es biológicamente efectiva, pero no es viable comercialmente, debido al elevado precio de adquisición. Los aceites vegetales y el aceite de pescado son suplementos más asequibles. Se ha demostrado que la incorporación en la ingesta de suplementos con aceites de pescado (Shingfield et al., 2006; Cruz-Hernández et al., 2007) aumenta el contenido de ALC, sin producir cambios en las características organolépticas de la leche, ni en productos derivados (Baer et al., 2001; Ramaswamy et al., 2001; Campbell et al., 2003; Caroprese et al., 2013). Los ácidos grasos poli-insaturados que contienen los aceites de pescado, como C20 - C22 incluyendo a los ácidos omega eicosapentanoico (EPA, C20:5 n-3) y docosahexaenoico (DHA, C22:6 $\mathrm{n}-3)$, inhiben las reductasas implicadas en la etapa final de biohidrogenación (conversión de ATV a esteárico), favoreciendo de esta forma la acumulación de ATV en el líquido ruminal (Chow et al., 2004; AbuGhazaleh y Jenkins, 2008; Murphy et al., 2008).

Una manera de optimizar la producción ruminal de ATV precursor del ALC-c9t1, ha sido la combinación de aceites de origen vegetal (como sustrato, para formación de ATV) con aceite de pescado o suplementos de origen marino (como inhibidores del paso final de la biohidrogenación). Cuando se evaluó el efecto de la suplementación con $0,8 \mathrm{~kg}$ /día de aceite de girasol (AG), combinado con $0,24 \mathrm{~kg} /$ día de aceite de pescado (AP), este último aumentó en $37 \%$ el contenido de ALC-c9t111 en leche, al pasar de 2,86 a 3,92 por $100 \mathrm{~g}$ de ácidos grasos (Gagliostro et al., 2006). Se encontraron diferencias para niveles de ALC-c9t11 en leche, siendo menor este valor con la grasa de palma al compararla con aceite de girasol (2,7\% de la MS) más alga (DHA 0,4\% de la MS) y aceite de lino (2,7\% de la MS) más alga $(0,4 \%$ de la MS), presentando valores de 1,0; 1,8 y $1,6 \%$, respectivamente (Angulo et al., 2012a).

El efecto de la suplementación con AG insaturados sobre la composición de ácidos grasos (AG) de la leche, ha sido ampliamente revisado (Chilliard et al., 2001; 2007a). Estos generalmente aumentan el porcentaje de AG C18 en la leche y disminuyen los AG de cadena corta y media, lo que puede ser debido a una inhibición en la síntesis de novo por los AG de cadena larga (Barber et al., 1997), o por sustitución de AG de cadena corta y media por AG de cadena larga sobre los triglicéridos de la leche (Hansen y Knudsen, 1987; Stoffel et al., 2015).

La suplementación con AG insaturados procedentes de aceite vegetal o de pescado disminuyen la grasa de la leche, sin ningún cambio en la producción o en otros componentes de esta (Bauman y Griinari, 2001). Diferentes publicaciones (Harvatine y Bauman, 2006; Gervais et al., 2009) han mostrado que ALC trans10, cis 12 disminuye la grasa de la leche, a través de una baja regulación en la transcripción de las enzimas y proteínas que participan en la síntesis de lípidos en la glándula mamaria (Shingfield et al., 2010; Maxin et al., 2011); recientemente se encontró que ALC trans10, cis 12 y ácidos grasos de cadena larga de la familia n-3 (DHA), podrían ser considerados como posibles supresores de la grasa de la leche, mediado en parte por una disminución en la proteína 1 unida al elemento de respuesta de los esteroles (SREBP1), que juega un papel crítico en la regulación de la dieta sobre los genes lipogénicos, especialmente aquellos asociados con la síntesis de novo (Angulo et al., 2012b).

Un estudio en el que se adicionó $0,5 \%$ de aceite de pescado (AP), combinado con aceite de girasol al 3,0\% del consumo de MS, en raciones de vacas lecheras que consumían una dieta de $50 \%$ de forraje (heno y ensilaje de cebada y alfalfa) y $50 \%$ de concentrado (grano de cebada y maíz), permitió obtener una composición de grasa de leche estable con aproximadamente $4 \%$ de ATV y $2 \%$ de ALC-c9t11, con tan solo una reducción en la grasa de la leche del $11 \%$, al compararla con el período en pretratamiento (Cruz- Hernández et al., 2007).

Los inconvenientes asociados al uso de aceite de pescado, son su baja palatabilidad, su elevado costo, la variabilidad estacional en sus AG constitutivos por la diversidad biológica de las especies marinas capturadas para su obtención, la falta de un suministro constante de este insumo por parte de los laboratorios o empresas 
proveedoras, la existencia de una restricción a su uso en algunos países para alimentación de rumiantes, más un cierto riesgo de desvíos en la fermentación ruminal hacia la producción de ciertos AG no deseados como el C18:1 trans 10, fundamentalmente en los ovinos (Gómez-Cortés, 2010). La generación de una mayor cantidad de AG relacionados con alteraciones del metabolismo lipídico (C18:1 trans10 y ALC-c9t11), sugirió que la adición de pequeñas cantidades de aceite de pescado a la ración de ovinos, afectaría en mayor medida al ecosistema ruminal que la incorporación a la dieta de mayores cantidades de aceites de oleaginosas como el girasol o la soja (Gómez-Cortés, 2010).

El ácido linolénico (18:3 n-3) contenido en el aceite de lino, también presenta potencialidad para incrementar los niveles de ALC-c9t11 en la grasa láctea (Gómez-Cortes et al., 2008) y en el fluido ruminal con la formación de ATV y un menor riesgo de incrementar el 18:1 trans 10. La suplementación con aceite de lino puede también reducir la relación omega-6/omega-3 en leche de vacas (Gagliostro, 2004a), cabras (Gagliostro, 2004b) y ovejas (GómezCortés, 2010).

Estudios in vitro (Castillo-Vargas, 2012) demostraron que la sustitución parcial de 18:2 por 18:3, incrementó la tasa de conversión del 18:2 a ALC-c9t11 y de ALC-c9t11 a ATV. La mayor tasa de isomerización del 18:2 se obtuvo al combinarlo con el 18:3, lo que implicaría que la desaparición del 18:2 del fluido ruminal resultaría mayor cuando se encuentra en mezcla con 18:3 que solo. Razón por la cual se desarrollan trabajos de investigación que mezclan aceite de soja, rico en ácido linoleico (C18:2 cis9, cis12), con aceite de lino, fuente de ácido linolénico (C18:3 cis9, cis12, cis 15), buscando generar una leche funcional, pero manteniendo niveles bajos de C18:1 trans 10 , lo que podría atenuar la inhibición de la síntesis de novo mamaria y mantener niveles cercanos al 3\% de grasa en la leche o mayores. En este sentido, Gagliostro y Antonacci (2013) suplementaron vacas lecheras con una mezcla de aceites de soja - lino en proporción 70:30, suministrando $0,7 \mathrm{~kg} / \mathrm{vaca} /$ día, durante veintisiete días, y aumentaron en la leche el ALC-c9t11 de $1,24 \%$ que se tenía inicialmente a $3,13 \%$, al final del ensayo.

Se ha demostrado que la suplementación con aceites vegetales ricos en AG poliinsaturados, no solo permite aumentar los niveles de ALC-c9t11, sino que también aumenta ATV, AG insaturados (moni y poliinsaturados) y disminuye los AG saturados (Cuadro 2), tanto en leche como en queso, sin afectar las características sensoriales del queso (VargasBello-Pérez et al., 2015), con un impacto alto en la composición de la grasa y su efecto sobre la salud humana. Asimismo, la suplementación con aceites ricos en AG poliinsaturados, disminuye el porcentaje de grasa en leche, aunque en trabajos recientes un aumento en la producción de leche con la suplementación con aceites ricos en AG poliinsaturados, conllevó a que el rendimiento en producción de grasa ( $\mathrm{kg} /$ día) no se viera afectado (Cuadro 2) (Boerman y Lock, 2014; Saliba et al., 2014).

Un aspecto importante a tener en cuenta en la alimentación de los animales rumiantes es que, debido al efecto inhibidor de los lípidos sobre el metabolismo microbiano, un aporte de alimentos con elevado contenido en grasa puede provocar una inhibición de la fermentación ruminal, disminuyendo significativamente la digestibilidad y el consumo de alimento (Harfoot y Hazlewood, 1997). Generalmente, se recomienda que la grasa total no exceda del 6-7\% de la MS de la dieta, de otra forma puede ocurrir una depresión en el consumo de alimento (NRC, 2001).

\section{CONSIDERACIONES FINALES}

De acuerdo con la revisión realizada, la suplementación con lípidos de origen vegetal, fuente de ácidos grasos insaturados, permite aumentar la concentración de ALC-c9t11 y disminuir la proporción de AG saturados en la leche, pero la respuesta varía de acuerdo con la fuente de grasa empleada, su nivel y la interacción con la dieta basal.

En Colombia la producción de leche se realiza con animales bajo pastoreo de gramínea sola o en mezcla con leguminosas, dentro de los que se encuentran los sistemas silvopastoriles intensivos (SSPi), con o sin suplementación con alimentos concentrados. La aplicación de estrategias nutricionales, como la suplementación lipídica, para producir leche más saludable, conlleva a que se desarrollen estudios sobre las características de la leche en relación con la composición de la grasa (proporción de nutrientes funcionales y AG insaturados) y la variación que se desprende de los sistemas de producción con su 
Cuadro 2. Variación en el porcentaje de ácido linoleico conjugado (ALC)-c9t11, ácido transvaccénico (ATV), ácidos grasos (AG) insaturados, saturados del total de grasa de la leche, \% grasa, producción de leche y rendimiento en grasa, en la leche de vaca, suplementadas con diferentes fuentes de AG. 2015.

Table 2. Change in the percentage of conjugated linoleic acid (CLA)-c9t11, transvaccenic acid (TVA), unsaturated fatty acids (FA), saturated from the total milk fat, $\%$ fat, milk production, and milk fat yield in cow's milk supplemented with different sources of FA. 2015.

\begin{tabular}{|c|c|c|c|c|c|c|c|c|c|}
\hline Autor & Tratamiento & $\begin{array}{l}\text { Aceite } \\
\% \text { MS } \\
\text { dieta }\end{array}$ & $\begin{array}{l}\text { ALC- } \\
\text { c9t11 }\end{array}$ & ATV & $\begin{array}{c}\text { Insatu- } \\
\text { rados }\end{array}$ & $\begin{array}{l}\text { Satu- } \\
\text { rados }\end{array}$ & $\begin{array}{c}\text { Grasa } \\
\text { leche } \\
\%\end{array}$ & $\begin{array}{l}\text { Prod. } \\
\text { leche } \\
\mathrm{kg} / \mathrm{d}\end{array}$ & $\begin{array}{c}\text { Grasa } \\
\mathrm{kg} / \mathrm{d}\end{array}$ \\
\hline \multirow{3}{*}{$\begin{array}{l}\text { Vargas-Bello- } \\
\text { Pérez et al. } \\
(2015)\end{array}$} & Control (sin aceite) & & 0,31 & 1,53 & 31,79 & 68,21 & & & 0,870 \\
\hline & Aceite de soya $500 \mathrm{~g} / \mathrm{a} / \mathrm{d}^{*}$ & $2,6 \%$ & 0,27 & 4,44 & 41,56 & 58,44 & & & 0,780 \\
\hline & Aceite palma $500 \mathrm{~g} / \mathrm{a} / \mathrm{d}$ & $2,6 \%$ & 0,12 & 1,33 & 32,65 & 67,35 & & & 0,650 \\
\hline \multirow{3}{*}{$\begin{array}{l}\text { Boerman y } \\
\text { Lock (2014) }\end{array}$} & Control (vainas de soja) & & 0,35 & 0,62 & & & 3,30 & 39,5 & 1,300 \\
\hline & AG de soja destilada (AG libres) & $2,0 \%$ & 0,79 & 1,54 & & & 3,18 & 42,0 & 1,340 \\
\hline & Aceite de soja (AG como TG**) & $2,0 \%$ & 0,83 & 1,70 & & & 3,11 & 41,4 & 1,290 \\
\hline \multirow{6}{*}{$\begin{array}{l}\text { Saliba et al. } \\
\text { (2014) }\end{array}$} & Sin aceite de semilla Lino & & & & & & & & \\
\hline & Forraje:Concentrado 70:30 & $0 \%$ & 0,51 & 1,13 & 36,11 & 63,89 & 4,22 & 25,4 & 1,046 \\
\hline & Forraje:Concentrado 30:70 & $0 \%$ & 0,36 & 0,64 & 37,55 & 62,54 & 3,76 & 32,2 & 1,165 \\
\hline & Con aceite de semilla Lino & & & & & & & & \\
\hline & Forraje:Concentrado 70:30 & $3,0 \%$ & 0,88 & 2,17 & 48,96 & 51,04 & 4,07 & 26,9 & 1,106 \\
\hline & Forraje:Concentrado 30:70 & $3,0 \%$ & 0,51 & 1,02 & 46,67 & 53,33 & 3,37 & 34,1 & 1,160 \\
\hline \multirow{2}{*}{$\begin{array}{l}\text { Aprianita et al. } \\
(2014)\end{array}$} & Control (sin aceite) & & 0,4 & 1,7 & 25,2 & 74,8 & 4,1 & 32,3 & 1,346 \\
\hline & Aceite semilla algodón $(800 \mathrm{~g} / \mathrm{a} / \mathrm{d})$ & & 1,8 & 4,5 & 36,6 & 63,4 & 3,4 & 35,4 & 1,224 \\
\hline \multirow{10}{*}{$\begin{array}{l}\text { Ferlay et al. } \\
\text { (2013) }\end{array}$} & Heno:Concentrado 50:50 & & & & & & & & \\
\hline & $0 \%$ semilla de lino extruida & $0 \%$ & 0,578 & 1,65 & 24,32 & 69,9 & 3,59 & 26,1 & 0,936 \\
\hline & $5 \%$ semilla de lino extruida & $5 \%$ & 0,915 & 2,95 & 34,40 & 59,8 & 3,50 & 25,8 & 0,905 \\
\hline & $10 \%$ semilla de lino extruida & $10 \%$ & 1,640 & 5,61 & 42,43 & 52,0 & 350 & 28,3 & 0,981 \\
\hline & $15 \%$ semilla de lino extruida & $15 \%$ & 1,122 & 3,20 & 48,17 & 45,8 & 2,91 & 28,0 & 0,804 \\
\hline & Ensilaje maíz:Concentrado 60:40 & & & & & & & & \\
\hline & $0 \%$ semilla de lino extruida & $0 \%$ & 0,61 & 1,54 & 25,9 & 69,0 & 3,38 & 25,3 & 0,858 \\
\hline & $5 \%$ semilla de lino extruida & $5 \%$ & 0,71 & 1,95 & 34,1 & 60,8 & 3,07 & 25,2 & 0,745 \\
\hline & $10 \%$ semilla de lino extruida & $10 \%$ & 0,77 & 2,31 & 45,1 & 48,9 & 2,71 & 23,6 & 0,646 \\
\hline & $15 \%$ semilla de lino extruida & $15 \%$ & 0,92 & 3,12 & 46,2 & 48,1 & 3,12 & 25,1 & 0,799 \\
\hline \multirow{3}{*}{$\begin{array}{l}\text { Angulo et al. } \\
(2012 a)\end{array}$} & Grasa de palma $(3,1 \%$ de la MS $)$ & $3,1 \%$ & 1,0 & 1,5 & 32,1 & 67,9 & & & \\
\hline & Aceite girasol $(2,7 \%)+$ DHA alga $(0,4 \%)$ & $3,1 \%$ & 1,6 & 4,7 & 47,5 & 52,5 & & & \\
\hline & Aceite de lino $(2,7 \%)+$ DHA alga $(0,4 \%)$ & $3,1 \%$ & 1,8 & 6,9 & 50,0 & 50,0 & & & \\
\hline \multirow{2}{*}{$\begin{array}{l}\text { Ferlay et al. } \\
(2010)\end{array}$} & Control (sin semilla lino) & $0 \%$ & 0,38 & 0,86 & 25,06 & 74,94 & 4,22 & 27,3 & 1,139 \\
\hline & Semilla de lino extruida & $5,0 \%$ & 1,51 & 4,51 & 42,64 & 57,36 & 3,73 & 29,2 & 1,079 \\
\hline \multirow{4}{*}{$\begin{array}{l}\text { Rego et al. } \\
(2009)\end{array}$} & Control (sin aceite) & & 1,18 & 2,70 & & 63,0 & 3,75 & 22,2 & 0,820 \\
\hline & Aceite de colza $0,5 \mathrm{~kg} / \mathrm{a} / \mathrm{d}$ & & 1,14 & 2,53 & & 52,5 & 3,33 & 21,9 & 0,720 \\
\hline & Aceite de girasol $0,5 \mathrm{~kg} / \mathrm{a} / \mathrm{d}$ & & 1,60 & 3,31 & & 51,3 & 3,27 & 22,0 & 0,700 \\
\hline & Aceite de lino $0,5 \mathrm{~kg} / \mathrm{a} / \mathrm{d}$ & & 1,54 & 3,69 & & 52,4 & 3,59 & 22,2 & 0,780 \\
\hline \multirow{4}{*}{$\begin{array}{l}\text { Cruz-Henández } \\
\text { et al. (2007) }\end{array}$} & Control (sin aceite) & $0 \%$ & 0,42 & 0,80 & & 68,90 & 3,81 & 27,26 & 1,038 \\
\hline & $1,5 \%$ aceite girasol $+0,5 \%$ aceite pescado & $2,0 \%$ & 2,15 & 3,08 & & 62,80 & 3,50 & 31,31 & 1,095 \\
\hline & $3,0 \%$ aceite girasol $+0,5 \%$ aceite pescado & $3,5 \%$ & 2,09 & 3,95 & & 56,56 & 3,63 & 26,55 & 0,963 \\
\hline & $4,0 \%$ aceite girasol $+0,5 \%$ aceite pescado & $4,5 \%$ & 2,78 & 6,62 & & 49,29 & 3,39 & 29,51 & 1,000 \\
\hline
\end{tabular}

$* \mathrm{~g} / \mathrm{a} / \mathrm{d}=$ gramos/animal/día, $* * \mathrm{TG}=$ triglicéridos $/ \mathrm{g} / \mathrm{a} / \mathrm{d}=\mathrm{g} /$ animal $/ \mathrm{day}, * * \mathrm{TG}=$ triglycer. 
alimentación característica; evaluar diferentes fuentes de AG insaturados para incrementar la presencia de nutrientes funcionales y conocer los efectos que se ocasionan sobre la fermentación ruminal, ayudados de la técnica in vitro de producción de gas y así poder seleccionar la mejor opción a probar en finca, buscando un producto diferencial, con un impacto alto en la composición de la grasa y su efecto sobre la salud humana.

\section{LITERATURA CITADA}

AbuGhazaleh, A.A., and T.C. Jenkins. 2004. Disappearance of docosahexaenoic and eicosapentaenoic acids from cultures of mixed ruminal microorganisms. J. Dairy Sci. 87:645-651.

AbuGhazaleh, A.A., and T.C. Jenkins. 2008. Effect of fish oil and sunflower oil supplementation on milk conjugated linoleic acid content for grazing dairy cows. Anim. Feed Sci. Technol. 141:220-232.

AbuGhazaleh, A.A., D.J. Schingoethe, A.R. Hippen, and K.F. Kalscheur. 2003. Milk conjugated linoleic acid response to fish oil supplementation of diets differing in fatty acid profiles. J. Dairy Sci. 86:944-953.

AbuGhazaleh, A.A., D.J. Schingoethe, A.R. Hippen, and K.F. Kalscheur. 2004. Conjugated linoleic acid increases in milk when cows fed fish meal and extruded soybeans for an extended period of time. J. Dairy Sci. 87:17581766.

Angulo, J., B. Hiller, M. Olivera, L. Mahecha, D. Dannenberger, G. Nuernberg, B. Losand, and K. Nuernberg. 2012a. Dietary fatty acid intervention of lactating cows simultaneously affects lipid profiles of meat and milk. J. Sci. Food Agric. 92:2968-2974.

Angulo, J., L. Mahecha, K. Nuernberg, G. Nuernberg, D. Dannenberger, M. Olivera, M. Boutinaud, C. Leroux, E. Albrecht, and L. Bernard. 2012b. Effects of polyunsaturated fatty acids from plant oils and algae on milk fat yield and composition are associated with mammary lipogenic and SREBF1 gene expression. Animal 6:1961-1972.

Aprianita, A., O.N. Donkor, P.J. Moate, S.R.O. Williams, M.J. Auldist, J.S. Greenwood, M.C. Hannah, W.J. Wales, and T. Vasiljevic. 2014. Effects of dietary cottonseed oil and tannin supplements on protein and fatty acid composition of bovine milk. J. Dairy Res. 81:183-92.
Atkinson, R.L., E.J. Scholljegerdes, S.L. Lake, V. Nayigihugu, B.W. Hess, and D.C. Rule. 2006. Site and extent of digestion, duodenal flow, and intestinal disappearance of total and esterified fatty acids in sheep fed a high-concentrate diet supplemented with high-linoleate safflower oil. J. Anim. Sci. 84:387-396.

Baer, R., J. Ryali, D. Schingoethe, K. Kasperson, D. Donovan, A. Hippen, and S. Franklin. 2001. Composition and properties of milk and butter from cows fed fish oil. J. Dairy Sci. 84:345-353.

Barber, M.C., R.A. Clegg, M.T. Travers, and R.G. Vernon. 1997. Lipid metabolism in the lactating mammary gland. Biochim. Biophys. Acta - Lipids Lipid Metab. 1347:101-126.

Bauman, D.E., L.H. Baumgard, B.A. Corl, and J.M. Griinari. 1999. Biosynthesis of conjugated linoleic acid in ruminants. Proc. Am. Soc. Anim. Sci. 77:1-15.

Bauman, D., B. Corl, and D. Paterson. 2003a. The biology of conjugated linoleic acids in ruminants. In: J.L. Sébédio, et al., editors, Advances in conjugated linoleic acids research. AOCS press, Champain, IL, USA. p. 146-173.

Bauman, D., and J. Griinari. 2001. Regulation and nutritional manipulation of milk fat: low-fat milk syndrome. Livest. Prod. Sci. 70:15-29.

Bauman, D.E., and A.L. Lock. 2006. Conjugated linoleic acid: Biosynthesis and nutricional significance. In: P.F. Fox, and P.L.H. McSweeney, editors, Advanced dairy chemistry. Vol. 2: Lipids. 3rd ed. Springer US, NY, USA. p. 93-136.

Bauman, D., J. Perfield II, M. de Veth, and A. Lock. 2003b. New perspectives on lipid digestion and metabolism in ruminants. In Cornell University, editor, Proc. Cornell Nutr. Conf. Cornell University, NY, USA. p. 175-189.

Beam, T.M., T.C. Jenkins, P.J. Moate, R.A. Kohn, and D.L. Palmquist. 2000. Effects of amount and source of fat on the rates of lipolysis and biohydrogenation of fatty acids in ruminal contents. J. Dairy Sci. 83:2564-2573.

Belury, M.A. 2002. Dietary conjugated linoleic acid in health: physiological effects and mechanisms of action. Annu. Rev. Nutr. 22:505-531.

Bernal-Santos, G., J.W. Perfield, D.M. Barbano, D.E. Bauman, and T.R. Overton. 2003. Production responses of dairy cows to dietary supplementation with conjugated linoleic acid (CLA) during the transition period and early lactation. J. Dairy Sci. 86: 3218-3228.

Agron. Mesoam. 27(2):421-437. 2016 ISSN 2215-3608 
Bichi, E., P.G. Toral, G. Hervas, P. Frutos, P. Gomez-Cortes, M. Juarez, and M.A. De la Fuente. 2012. Inhibition of $\Delta 9$-desaturase activity with sterculic acid: effect on the endogenous synthesis of cis-9 18:1 and cis-9, trans-11 18:2 in dairy sheep. J. Dairy Sci. 95:52425252.

Boerman, J.P., and A.L. Lock. 2014. Effect of unsaturated fatty acids and triglycerides from soybeans on milk fat synthesis and biohydrogenation intermediates in dairy cattle. J. Dairy Sci. 97:7031-7042.

Buccioni, A., M. Decandia, S. Minieri, G. Molle, and A. Cabiddu. 2012. Lipid metabolism in the rumen: New insights on lipolysis and biohydrogenation with an emphasis on the role of endogenous plant factors. Anim. Feed Sci. Technol. 174:1-25.

Cabiddu, A., G. Molle, M. Decandia, S. Spada, M. Fiori, G. Piredda, and M. Addis. 2009. Responses to condensed tannins of flowering sulla (Hedysarum coronarium L.) grazed by dairy sheep. Livest. Sci. 123:230-240.

Cabiddu, A., L. Salis, J.K.S. Tweed, G. Molle, M. Decandia, and M.R.F. Lee. 2010. The influence of plant polyphenols on lipolysis and biohydrogenation in dried forages at different phenological stages: in vitro study. J. Sci. Food Agric. 90:829-835.

Campbell, W., M. a Drake, and D.K. Larick. 2003. The impact of fortification with conjugated linoleic acid (CLA) on the quality of fluid milk. J. Dairy Sci. 86:43-51.

Caroprese, M., A. Sevi, R. Marino, A. Santillo, A. Tateo, and M. Albenzio. 2013. Composition and textural properties of mozzarella cheese naturally-enriched in polyunsaturated fatty acids. J. Dairy Res. 80:276-282.

Castillo-Vargas, J.A. 2012. Cinética de biohidrogenación in vitro de ácidos grasos poliinsaturados en fluido ruminal. Tesis M.Sc., Universidad Nacional de Colombia, Bogotá, COL.

Castro, T., T. Manso, V. Jimeno, M. Del Alamo, and A.R. Mantecón. 2009. Effects of dietary sources of vegetable fats on performance of dairy ewes and conjugated linoleic acid (CLA) in milk. Small Rumin. Res. 84:47-53.

Chilliard, Y., and A. Ferlay. 2004. Dietary lipids and forages interactions on cow and goat milk fatty acid composition and sensory properties. Reprod. Nutr. Dev. 44:467-92.

Chilliard, Y., A. Ferlay, and M. Doreau. 2001. Effect of different types of forages, animal fat or marine oils in cow's diet on milk fat secretion and composition, especially conjugated linoleic acid (CLA) and polyunsaturated fatty acids. Livest. Prod. Sci. 70:3148

Chilliard, Y., A Ferlay, J. Rouel, and G. Lamberet. 2003. A review of nutritional and physiological factors affecting goat milk lipid synthesis and lipolysis. J. Dairy Sci. 86:1751-1770.

Chilliard, Y., F. Glasser, F. Enjalbert, A. Ferlay, F. Bocquier, y P. Schmidely. 2007a. Resultados recientes sobre los efectos de la alimentación en la composición en ácidos grasos de la leche de vaca, cabra y oveja. Rev. Arg. Prod. Anim. 27:197-213.

Chilliard, Y., F. Glasser, A. Ferlay, L. Bernard, J. Rouel, and M. Doreau. 2007b. Diet, rumen biohydrogenation and nutritional quality of cow and goat milk fat. Eur. J. Lipid Sci. Technol. 109:828-855.

Chouinard, P.Y., L. Corneau, W.R. Butler, Y. Chilliard, J.K. Drackley, and D.E. Bauman. 2001. Effect of dietary lipid source on conjugated linoleic acid concentrations in milk fat. J. Dairy Sci. 84:680-690.

Chow, T.T., V. Fievez, A.P. Moloney, K. Raes, D. Demeyer, and S. De Smet. 2004. Effect of fish oil on in vitro rumen lipolysis, apparent biohydrogenation of linoleic and linolenic acid and accumulation of biohydrogenation intermediates. Anim. Feed Sci. Technol. 117(1-2):1-12.

CNL (Consejo Nacional Lácteo). 2010. Acuerdo de competitividad de la cadena lacteal colombiana. CNL, Bogota, COL.

Collomb, M., R. Sieber, and U. Bütikofer. 2004a. CLA isomers in milk fat from cows fed diets with high levels of unsaturated fatty acids. Lipids 39:355-364.

Collomb, M., H. Sollberger, U. Bütikofer, R. Sieber, W. Stoll, and W. Schaeren. 2004b. Impact of a basal diet of hay and fodder beet supplemented with rapeseed, linseed and sunflowerseed on the fatty acid composition of milk fat. Int. Dairy J. 14:549-559.

Corl, B.A., L.H. Baumgard, J.M. Griinari, P. Delmonte, K.M. Morehouse, M.P. Yurawecz, and D.E. Bauman. 2002. Trans-7, cis-9 CLA is synthesized endogenously by delta9-desaturase in dairy cows. Lipids 37:681-8.

Cruz-Hernandez, C., J.K.G. Kramer, J.J. Kennelly, D.R. Glimm, B.M. Sorensen, E.K. Okine, L. a Goonewardene, and R.J. Weselake. 2007. Evaluating the conjugated linoleic acid and trans 18:1 isomers in milk fat of dairy cows fed increasing amounts of sunflower oil and a constant level of fish oil. J. Dairy Sci. 90:3786-3801. 
Dehority, B. 2003. Rumen microbiology. Nottingham University Press, Nottingham, GBR.

Dhiman, T.R., L.D. Satter, M.W. Pariza, M.P. Galli, K. Albright, and M.X. Tolosa. 2000. Conjugated linoleic acid (CLA) content of milk from cows offered diets rich in linoleic and linolenic acid. J. Dairy Sci. 83:1016-1027.

Dohme, F., V. Fievez, K. Raes, and D.I. Demeyer. 2003. Increasing levels of two different fish oils lower ruminal biohydrogenation of eicosapentaenoic and docosahexaenoic acid in vitro. Anim. Res. 52:309. 320 .

Ferlay, A., M. Doreau, C. Martin, and Y. Chilliard. 2013. Effects of incremental amounts of extruded linseed on the milk fatty acid composition of dairy cows receiving hay or corn silage. J. Dairy Sci. 96:65776595.

Ferlay, A., B. Martin, S. Lerch, M. Gobert, P. Pradel, and Y. Chilliard. 2010. Effects of supplementation of maize silage diets with extruded linseed, vitamin $\mathrm{E}$ and plant extracts rich in polyphenols, and morning v. evening milking on milk fatty acid profiles in Holstein and Montbéliarde cows. Anim. 4:627-640.

Fukuda, S., Y. Suzuki, M. Murai, N. Asanuma, and T. Hino. 2006. Isolation of a novel strain of Butyrivibrio fibrisolvens that isomerizes linoleic acid to conjugated linoleic acid without hydrogenation, and its utilization as a probiotic for animals. J. Appl. Microbiol. 100: 787-794.

Gagliostro, G. A. 2004a. Control nutricional del contenido de ácido linoleico conjugado (CLA) en leche y su presencia en alimentos naturales funcionales. 2. Producción de leche alto CLA a través de la suplementación estratégica de la vaca lechera. Rev. Arg. Prod. Anim. 24:137-163.

Gagliostro, G.A. 2004b. Control nutricional del contenido de ácido linoleico conjugado (CLA) en leche y su presencia en alimentos naturales funcionales. 3. Producción de leche alto CLA a través de la suplementación estratégica de cabra. Rev. Arg. Prod. Anim. 24:165-185.

Gagliostro, G.A. 2011. Obtención de lácteos funcionales naturales. En: C.A. Cangiano, y M.A. Brizuela, editores, Producción animal en pastoreo. 2da. ed INTA, Balcarce. ARG. p. 425-445.

Gagliostro, G.A., and L.. Antonacci. 2013. Lácteos funcionales en Santa Fé caso rocío del campo: una leche única para elaboración de productos cualitativamente diferenciados con ventajas para la salud de los consumidores. Rev. Visión Rural 99:19-20.

Gagliostro, G.A., A. Rodriguez, P. Pellegrini, G. Musset, P. Gatti, R. Castañeda, D.A. Garciarena, M. Oporto, H.H. Fernández, A. Ferlay, and Y. Chilliard. 2006. Effects of sunflower oil or seeds combined or not with fish oil on conjugated linoleic acid in milk fat from grazing dairy cows. Rev. Arg. Prod. Anim. 26(Suplem I):99-100

Gervais, R., J.W. McFadden, A.J. Lengi, B.A. Corl, and P.Y. Chouinard. 2009. Effects of intravenous infusion of trans-10, cis-12 18:2 on mammary lipid metabolism in lactating dairy cows. J. Dairy Sci. 92:5167-77.

Giesy, J.G., M.A. McGuire, B. Shafii, and T.W. Hanson. 2002. Effect of dose of calcium salts of conjugated linoleic acid (CLA) on percentage and fatty acid content of milk fat in midlactation Holstein cows. J. Dairy Sci. 85:2023-2029.

Gómez-Cortés, P. 2010. Efecto de la suplementación de la dieta ovina con distintas fuentes lipídicas sobre el perfil de ácidos grasos de la leche. Universidad Complutense de Madrid, Madrid, ESP.

Gómez-Cortés, P., P. Frutos, a R. Mantecón, M. Juárez, M. A. de la Fuente, and G. Hervás. 2008. Milk production, conjugated linoleic acid content, and in vitro ruminal fermentation in response to high levels of soybean oil in dairy ewe diet. J. Dairy Sci. 91:1560-1569.

Hansen, H.O., and J. Knudsen. 1987. Effect of exogenous long-chain fatty acids on lipid biosynthesis in dispersed ruminant mammary gland epithelial cells: esterification of long-chain exogenous fatty acids. J. Dairy Sci. 70:1344-1349.

Harfoot, C., and G. Hazlewood. 1988. Lipid metabolism in the rumen. In: P.N. Hobson, and C.S. Stewart, editors, The rumen microbial ecosystem. Elsevier Science Publishing, N.Y., USA. p. 285-322.

Harfoot, C., and G. Hazelewood. 1997. Lipid metabolism in the rumen. In: P. Hobson, and C.S. Stewart, editors, The rumen microbial ecosystem. 2nd ed. Chapman \& Hall, London, GBR. p. 382-426.

Harvatine, K.J., and M.S. Allen. 2006. Fat supplements affect fractional rates of ruminal fatty acid biohydrogenation and passage in dairy cows. J. Nutr. 136:677-685.

Harvatine, K.J., and D.E. Bauman. 2006. SREBP1 and thyroid hormone responsive spot 14 (S14) are involved in the regulation of bovine mammary lipid synthesis during diet-induced milk fat depression and treatment with CLA. J. Nutr. 136:2468-2474. 
Hervás, G., P. Luna, A.R. Mantecon, N. Castañares, P. Frutos, M.A. De la Fuente, and M. Juárez. 2006. Effect of sunflower oil on sheep milk production and composition, and in vitro rumen fermentation. In: Uropean Federation for the Science and Technology of Lipids, editor, 4th Euro fed lipid congress - fats, oils and lipids for a healthier future- Workshop on "Biohydrogenation. German Chemical Society (GDCh). Madrid, ESP. p. 18.

Jacob, A.B., V. Balakrishnan, and C. Kathirvelan. 2012. Effect of amount and source of vegetable oils in a high fibrous cattle diet on in vitro rumen fermentation, nutrient degradability and rumen cis-9, trans-11 CLA concentration. J. Appl. Anim. Res. 40:148-153.

Jenkins, T.C. 1993. Lipid metabolism in the rumen. J. Dairy Sci. 76:3851-3863.

Jenkins, T.C., A. a Abughazaleh, S. Freeman, and E.J. Thies. 2006. The production of 10-hydroxystearic and 10-ketostearic acids is an alternative route of oleic acid transformation by the ruminal microbiota in cattle. J. Nutr. 136:926-931.

Jenkins, T.C., R.J. Wallace, P.J. Moate, and E.E. Mosley. 2008. Board-invited review: recent advances in biohydrogenation of unsaturated fatty acids within the rumen microbial ecosystem. J. Anim. Sci. 86:397-412.

Kelly, M.L., J.R. Berry, D.A. Dwyer, J.M. Griinari, P.Y. Chouinard, M.E. Van Amburgh, and D.E. Bauman. 1998. Dietary fatty acid sources affect conjugated linoleic acid concentrations in milk from lactating dairy cows. J. Nutr. 128:881-885.

Kepler, C.R., and S.B. Tove. 1967. Biohydrogenation of unsaturated fatty acids: III. Purification and properties of a linoleate $\Delta 12$-cis, $\Delta 11$-trans-isomerase from Butyrivibrio fibrisolvens. J. Biol. Chem. 242:5686-5692.

Khanal, R.C. 2004. Potential health benefits of conjugated linoleic acid (CLA): A review. Asian Australas. J. Anim. Sci. 17:1315-1328.

Khanal, R.C., and K.C. Olson. 2004. Factors affecting conjugated linoleic acid (CLA) content in milk, meat, and egg: A review. Pakistan J. Nutr. 3:2-98.

Kolver, E.S. 1997. Supplemental feeding strategies to increase the utilization of pasture nitrogen by high producing dairy cows. Ph.D. Diss., Pennsylvania State Univ., State College, PA, USA.

Kucuk, O., B.W. Hess, P.A. Ludden, and D.C. Rule. 2001. Effect of forage:concentrate ratio on ruminal digestion and duodenal flow of fatty acids in ewes. J. Anim. Sci. 79:2233-2240.
Lee, H.G., Z.S. Hong, J.H. Wang, C.X. Xu, Y.C. Jin, T.K. Kim, Y.J. Kim, M.K. Song, and Y.J. Choi. 2009. Milk conjugated linoleic acid (CLA) profile and metabolic responses of dairy cows fed with high-temperaturemicro-time (HTMT) treated diets containing high quantity extruded soybean (ESB). Asian-Australas. J. Anim. Sci. 22:1504-1512.

Lee, M.R.F., S. A. Huws, N.D. Scollan, and R.J. Dewhurst. 2007a. Effects of fatty acid oxidation products (green odor) on rumen bacterial populations and lipid metabolism in vitro. J. Dairy Sci. 90:3874-3882.

Lee, Y.J., and T.C. Jenkins. 2011. Biohydrogenation of linolenic acid to stearic acid by the rumen microbial population yields multiple intermediate conjugated diene isomers. J. Nutr. 141:1445-1450.

Lee, M.R.F., L.J. Parfitt, N.D. Scollan, and F.. Minchin. 2007b. Lipolysis in red clover with different polyphenol oxidase activities in the presence and absence of rumen fluid. J. Sci. Food Agric. 87:13081314.

Lee, M.R.F., M.B. Scott, J.K.S. Tweed, F.R. Minchin, and D.R. Davies. 2008. Effects of polyphenol oxidase on lipolysis and proteolysis of red clover silage with and without a silage inoculant (Lactobacillus plantarum L54). Anim. Feed Sci. Technol. 144:125-136.

Lee, M.R.F., J.K.S. Tweed, A. Cookson, and M.L. Sullivan. 2010. Immunogold labelling to localize polyphenol oxidase (PPO) during wilting of red clover leaf tissue and the effect of removing cellular matrices on PPO protection of glycerol-based lipid in the rumen. J. Sci. Food Agric. 90:503-510.

Lee, M.R.F., J.K.S. Tweed, R.J. Dewhurst, and N.D. Scollan. 2006. Effect of forage: concentrate ratio on ruminal metabolism and duodenal flow of fatty acids in beef steers. Anim. Sci. 82:2233-2240.

Lee, M.R., J. Tweed, A. Moloney, and N. Scollan. 2005. The effects of fish oil supplementation on rumen metabolism and the biohydrogenation of unsaturated fatty acids in beef steers given diets containing sunflower oil. J. Anim. Sci. 80.

Lerch, S., A. Ferlay, K.J. Shingfield, B. Martin, D. Pomiès, and Y. Chilliard. 2012. Rapeseed or linseed supplements in grass-based diets: effects on milk fatty acid composition of Holstein cows over two consecutive lactations. J. Dairy Sci. 95:1956-1970.

Lock, A.L., and D.E. Bauman. 2004. Modifying milk fat composition of dairy cows to enhance fatty acids beneficial to human health. Lipids 39:1197-1206. 
Lock, A.L., and P.C. Garnsworthy. 2002. Independent effects of dietary linoleic and linolenic fatty acids on the conjugated linoleic acid content of cows' milk. Anim. Sci. 74:163-176.

Loor, J.J., K. Ueda, A. Ferlay, Y. Chilliard, and M. Doreau. 2004. Biohydrogenation, duodenal flow, and intestinal digestibility of trans fatty acids and conjugated linoleic acids in response to dietary forage:concentrate ratio and linseed oil in dairy cows. J. Dairy Sci. 87: 2472-85.

Maia, M.R.G., L.C. Chaudhary, C.S. Bestwick, A.J. Richardson, N. McKain, T.R. Larson, I. A. Graham, and R.J. Wallace. 2010. Toxicity of unsaturated fatty acids to the biohydrogenating ruminal bacterium, Butyrivibrio fibrisolvens. BMC Microbiol. 10:52.

Maxin, G., H. Rulquin, and F. Glasser. 2011. Response of milk fat concentration and yield to nutrient supply in dairy cows. Anim. 5:1299-1310.

McCrorie, T.A., E.M. Keaveney, J.M.W. Wallace, N. Binns, and M.B.E. Livingstone. 2011. Human health effects of conjugated linoleic acid from milk and supplements. Nutr. Res. Rev. 24:206-227.

McKain, N., K.J. Shingfield, and R.J. Wallace. 2010. Metabolism of conjugated linoleic acids and 18:1 fatty acids by ruminal bacteria: Products and mechanisms. Microbiol. 156:579-588.

Milner, J.A. 1999. Functional foods and health promotion. J. Nutr. 129:1395S-1397S.

Moon, C.D., D.M. Pacheco, W.J. Kelly, S.C. Leahy, D. Li, J. Kopecny, and G.T. Attwood. 2008. Reclassification of Clostridium proteoclasticum as Butyrivibrio proteoclasticus comb. nov., a butyrate-producing ruminal bacterium. Int. J. Syst. Evol. Microbiol. 58: 2041-2045

Mosley, E.E., G.L. Powell, M.B. Riley, and T.C. Jenkins. 2002. Microbial biohydrogenation of oleic acid to trans isomers in vitro. J. Lipid Res. 43:290-296.

Murphy, J.J., M. Coakley, and C. Stanton. 2008. Supplementation of dairy cows with a fish oil containing supplement and sunflower oil to increase the CLA content of milk produced at pasture. Livest. Sci. 116:332-337.

Nam, I.S., and P.C. Garnsworthy. 2007. Biohydrogenation of linoleic acid by rumen fungi compared with rumen bacteria. J. Appl. Microbiol. 103:551-556.

NRC (National Research Council). 2001. Nutrient requirements of dairy cattle. 7th rev. National Academy Press, WA, DC, USA.
Or-Rashid, M.M., O. Alzahal, and B.W. McBride. 2011. Comparative studies on the metabolism of linoleic acid by rumen bacteria, protozoa, and their mixture in vitro. Appl. Microbiol. Biotechnol. 89:387-395.

Owens, F.N., D.S. Secrist, W.J. Hill, and D.R. Gill. 1998. Acidosis in cattle: A review. J. Anim. Sci. 76:275-286.

Palmquist, D.L., A.L. Lock, K.J. Shingfield, and D.E. Bauman. 2005. Biosynthesis of conjugated linoleic acid in ruminants and humans. Adv. Food Nutr. Res. 50:179-217.

Pariza, M.W. 2004. Perspective on the safety and effectiveness of conjugated linoleic acid. Am. J. Clin. Nutr. 79:1132-1136.

Parodi, P.W. 2003. Conjugated linoleic acid in food. In: J. Sébédio, et al., editors, Advances in conjugated linoleic acid in food. AOCS Press, Champaign, IL, USA. p. 101-122.

Perfield, J.W., G. Bernal-Santos, T.R. Overton, and D.E. Bauman. 2002. Effects of dietary supplementation of rumen-protected conjugated linoleic acid in dairy cows during established lactation. J. Dairy Sci. 85: 2609-2617.

Piperova, L.S., J. Sampugna, B.B. Teter, K.F. Kalscheur, M.P. Yurawecz, Y. Ku, K.M. Morehouse, and R. A. Erdman. 2002. Duodenal and milk trans octadecenoic acid and conjugated linoleic acid (CLA) isomers indicate that postabsorptive synthesis is the predominant source of cis-9-containing CLA in lactating dairy cows. J. Nutr. 132:1235-1241.

Prandini, A., S. Sigolo, and G. Piva. 2009. Conjugated linoleic acid (CLA) and fatty acid composition of milk, curd and Grana Padano cheese in conventional and organic farming systems. J. Dairy Res. 76:278282.

Ramaswamy, N., R.J. Baer, D.J. Schingoethe, A.R. Hippen, K.M. Kasperson, and L.A. Whitlock. 2001. Composition and flavor of milk and butter from cows fed fish oil, extruded soybeans, or their combination. J. Dairy Sci. 84:2144-2151.

Rego, O.A., S.P. Alves, L.M.S. Antunes, H.J.D. Rosa, C.F.M. Alfaia, J.A.M. Prates, A.R.J. Cabrita, A.J.M. Fonseca, and R.J.B. Bessa. 2009. Rumen biohydrogenationderived fatty acids in milk fat from grazing dairy cows supplemented with rapeseed, sunflower, or linseed oils. J. Dairy Sci. 92:4530-4540.

Renna, M., M. Collomb, A. Münger, and U. Wyss. 2010. Influence of low-level supplementation of grazing dairy cows with cereals or sugar beet pulp on the 
concentrations of CLA isomers in milk. J. Sci. Food Agric. 90:1256-1267.

Saliba, L., R. Gervais, Y. Lebeuf, and P.Y. Chouinard. 2014. Effect of feeding linseed oil in diets differing in forage to concentrate ratio: 1 . Production performance and milk fat content of biohydrogenation intermediates of $\alpha$-linolenic acid. J. Dairy Res. 81:82-90.

Salter, A.M. 2013. Dietary fatty acids and cardiovascular disease. Anim. 7:163-171.

Sauvant, D., et P. Bas. 2001. La digestion des lipides chez le ruminant. Prod. Anim. 14:303-310.

Sauvant, D., F. Meschy, et D. Mertens. 1999. Les composantes de l'acidose ruminale et les effets acidogènes des rations. Prod. Anim. 12:49-60.

Secchiari, P., M. Antongiovanni, M. Mele, A. Serra, A. Buccioni, G. Ferruzzi, F. Paoletti, and F. Petacchi. 2003. Effect of kind of dietary fat on the quality of milk fat from Italian Friesian cows. Livest. Prod. Sci. $83: 43-52$

Shingfield, K.J., S. Ahvenjärvi, V. Toivonen, A. Ärölä, K.V.V. Nurmela, and P. Huhtanen. 2003. Effect of dietary fish oil on biohydrogenation of fatty acids and milk fatty acid content in cows. Anim. Sci. 77:165-179.

Shingfield, K.J., L. Bernard, C. Leroux, and Y. Chilliard. 2010. Role of trans fatty acids in the nutritional regulation of mammary lipogenesis in ruminants. Anim. 4:1140-1166.

Shingfield, K.J., M. Bonnet, and N.D. Scollan. 2013. Recent developments in altering the fatty acid composition of ruminant-derived foods. Animal 7:132-162.

Shingfield, K.J., Y. Chilliard, V. Toivonen, P. Kairenius, and D.I. Givens. 2008. Trans fatty acids and bioactive lipids in ruminant milk. Adv. Exp. Med. Biol. 606:3-65.

Shingfield, K.J., C.K. Reynolds, G. Hervás, J.M. Griinari, A.S. Grandison, and D.E. Beever. 2006. Examination of the persistency of milk fatty acid composition responses to fish oil and sunflower oil in the diet of dairy cows. J. Dairy Sci. 89:714-732.

Slyter, L.L. 1986. Ability of pH-selected mixed ruminal microbial populations to digest fiber at various $\mathrm{pHs}$. Appl. Environ. Microbiol. 52:390-391.

Stanton, C., J. Murphy, E. McGrath, R. Devery, J.L. Sébédio, W.W. Christie, and R. Adlof. 2003. Animal feeding strategies for conjugated linoleic acid enrichment of milk. In: J.L. Sébédio, et al., editors, Advances in conjugated linoleic acid research. AOCS Press, Champaign, IL, USA. p. 123-145.

Sterk, A., B.E.O. Johansson, H.Z.H. Taweel, M. Murphy, A.M. Van Vuuren, W.H. Hendriks, and J. Dijkstra.
2011. Effects of forage type, forage to concentrate ratio, and crushed linseed supplementation on milk fatty acid profile in lactating dairy cows. J. Dairy Sci. 94:6078-6091.

Stoffel, C.M., P.M. Crump, and L.E. Armentano. 2015. Effect of dietary fatty acid supplements, varying in fatty acid composition, on milk fat secretion in dairy cattle fed diets supplemented to less than $3 \%$ total fatty acids. J. Dairy Sci. 98:431-442.

Troegeler-Meynadier, A., L. Bret-Bennis, and F. Enjalbert. 2006. Rates and efficiencies of reactions of ruminal biohydrogenation of linoleic acid according to $\mathrm{pH}$ and polyunsaturated fatty acids concentrations. Reprod. Nutr. Dev. 46:713-724.

Van Nevel, C.J., and D.I. Demeyer. 1996. Influence of pH on lipolysis and biohydrogenation of soybean oil by rumen contents in vitro. Reprod. Nutr. Dev. 36:53-63.

Vargas-Bello-Pérez, E., K. Fehrmann-Cartes, G. ÍñiguezGonzález, P. Toro-Mujica, and P.C. Garnsworthy. 2015. Chemical composition, fatty acid composition, and sensory characteristics of Chanco cheese from dairy cows supplemented with soybean and hydrogenated vegetable oils. J. Dairy Sci. 98:111-117.

Vasta, V., H.P.S. Makkar, M. Mele, and A. Priolo. 2009a. Ruminal biohydrogenation as affected by tannins in vitro. Br. J. Nutr. 102:82-92.

Vasta, V., M. Mele, A. Serra, M. Scerra, G. Luciano, M. Lanza, and A. Priolo. 2009b. Metabolic fate of fatty acids involved in ruminal biohydrogenation in sheep fed concentrate or herbage with or without tannins. J. Anim. Sci. 87:2674-2684.

Wallace, R.J., L.C. Chaudhary, N. McKain, N.R. McEwan, A.J. Richardson, P.E. Vercoe, N.D. Walker, and D. Paillard. 2006. Clostridium proteoclasticum: A ruminal bacterium that forms stearic acid from linoleic acid. FEMS Microbiol. Lett. 265:195-201.

Wallace, R.J., N. McKain, K.J. Shingfield, and E. Devillard. 2007. Isomers of conjugated linoleic acids are synthesized via different mechanisms in ruminal digesta and bacteria. J. Lipid Res. 48:2247-2254. doi:10.1194/jlr.M700271-JLR200

Weiss, M.F., F.A. Martz, and C.L. Lorenzen. 2004a. Conjugated linoleic acid: historical context and implications. Prof. Anim. Sci. 20:118-126.

Weiss, M.F., F.A. Martz, and C.L. Lorenzen. 2004b. Conjugated linoleic acid: Implicated mechanisms related to cancer, atherosclerosis, and obesity. Prof. Anim. Sci. 20:127-135. 